\title{
A scoping review to identify competencies for transcatheter cardiovascular procedures
}

Hellmuth R. Muller Moran, MD, ${ }^{\mathrm{a}, \mathrm{b}}$ Meagane Maurice-Ventouris, BSc, ${ }^{\mathrm{b}}$ Mohammed Alharbi, MD, Jason M. Harley, MA, PhD, ${ }^{\mathrm{b}}$ and Kevin J. Lachapelle, MDCM, FACS, FRCPSC ${ }^{\mathrm{b}}$

\section{ABSTRACT}

Objectives: Transcatheter procedures are increasingly being recognized as a priority for cardiac surgeons and cardiac surgery trainees. The optimal method of teaching these procedures during residency training has not been established. We used an evidence-based approach to systematically review the literature and identify competencies to inform future paradigms of transcatheter training in cardiac surgery.

Methods: A scoping review was conducted to retrieve relevant literature on the performance of transcatheter cardiovascular procedures, identify competencies required by surgical residents learning to perform these procedures, and develop a preliminary list of competencies for consideration during transcatheter training. MEDLINE, Scopus, and ERIC were queried until April 1, 2020, using a systematic search strategy. No limitations were placed on publication date or type.

Results: A total of 1456 sources of evidence were retrieved. After deduplication and screening, there remained 33 that were included in the scoping review, published between 2006 and 2020. The distribution of publication types included 10 comparative studies ( $30.3 \%$ of total), 8 societal statements ( $24.2 \%$ of total), 5 surveys and 5 opinion articles (each $15.2 \%$ of total), 2 editorials and 2 descriptions of a simulator (each $6.1 \%$ of total), and 1 narrative review (3.0\% of total). From these, a total of 400 items were identified and organized into 97 competencies.

Conclusions: Evidence on the competencies required to perform transcatheter cardiovascular procedures is available from a variety of sources. The identified competencies may be a useful resource for developing curricula and teaching transcatheter procedures to cardiac surgery residents. (J Thorac Cardiovasc Surg 2022;164:(e457-69)

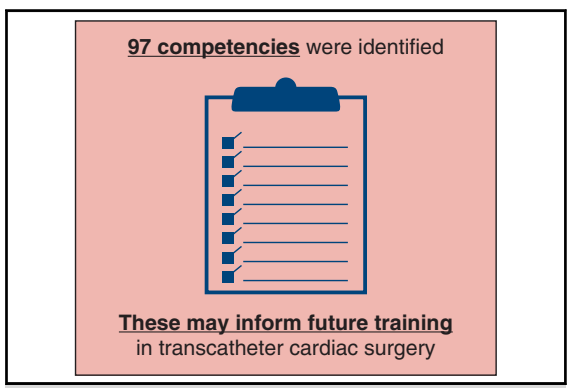

The identified competencies may inform future training in transcatheter cardiac surgery.

CENTRAL MESSAGE

This scoping review has identi-

fied relevant competencies that may facilitate evidence-based approaches to teaching transcatheter cardiovascular procedures to surgical residents.

\section{PERSPECTIVE}

A broad body of literature on performing transcatheter cardiovascular procedures is available. Lack of cohesion among sources of evidence may be impeding the efforts of cardiac surgeons to learn these procedures and teach them to residents. This scoping review has identified an evidence-based set of competencies to facilitate the teaching of transcatheter cardiovascular procedures.

See Commentaries on pages e 471 and $\mathbf{e} 472$.

The recent growth of endovascular therapies has led to significant changes in the way which care is delivered. Endovascular repair has emerged as an acceptable and sometimes preferable alternative to open surgery for disease

\footnotetext{
From the ${ }^{a}$ Department of Surgery, University of Manitoba, Winnipeg, Manitoba; and ${ }^{\mathrm{b}}$ Department of Surgery, McGill University, Montreal, Quebec, Canada.

Received for publication Aug 14, 2020; revisions received Oct 21, 2020; accepted for publication Nov 3, 2020; available ahead of print Nov 30, 2020.

Address for reprints: Kevin J. Lachapelle, MDCM, FACS, FRCPSC, Glen Campus The Royal Victoria Hospital, 1001 Decarie Blvd, Block C, C07.1284, Montreal,

Quebec, Canada, H4A 3J1 (E-mail: kevin.lachapelle@mcgill.ca). 0022-5223/\$36.00

Copyright (c) 2020 Published by Elsevier Inc. on behalf of The American Association for Thoracic Surgery

https://doi.org/10.1016/j.jtcvs.2020.11.096
}

of the thoracic aorta. ${ }^{1-4}$ Many cardiovascular diseases that were previously the domain of open surgery are also now treatable using transcatheter alternatives. Supported by results from randomized controlled trials, ${ }^{5-8}$ more transcatheter aortic valve replacements than open surgical aortic valve replacements now occur each year in the United States. ${ }^{9}$ Therapies are also available and being further developed for mitral and tricuspid valve disease, although their role in the clinical realm remains to be defined. ${ }^{10,11}$

As a result of these changes, the acquisition of transcatheter skills has become a priority for cardiac surgeons and cardiac surgery trainees. ${ }^{12}$ Surveys of cardiac surgery trainees have repeatedly indicated that current training 


\section{Abbreviation and Acronym}

TAVI $=$ transcatheter aortic valve implantation

experiences are largely heterogeneous and insufficient to meet the needs of most trainees. ${ }^{13-15}$ Despite calls for changes to the training of cardiac surgeons to meet this growing demand, ${ }^{16}$ there is no universal curriculum for trainees to begin developing proficiency in transcatheter cardiovascular procedures during residency. Training program personnel are frequently not experienced enough in transcatheter procedures to develop such a curriculum. This scoping review will identify literature describing relevant competencies for their eventual inclusion in such a training curriculum.

Scoping review methodology is useful for describing the available body of knowledge related to a given topic. Scoping reviews differ from other knowledge synthesis approaches in that they do not aim to answer a focused question using a specific type of publication (eg, meta-analyses of randomized controlled trials) but rather adopt a more general approach that includes identifying all available types of evidence and clarifying concepts or definitions such as by describing them in terms of key characteristics. ${ }^{17}$ The process is intended to be iterative and allows for adjustments in methodology as important concepts are clarified. These differences are reflected in the distinct nomenclature used when describing a scoping review, such as "information sources" in lieu of "databases," "sources of evidence" in lieu of "studies," "data charting" in lieu of "data abstraction," and "critical appraisal" in lieu of "risk of bias." ${ }^{18}$ Considering the evolving role of cardiac surgeons during transcatheter procedures, ${ }^{16,19}$ unclear meaning of commonly used phrases such as "wire skills," 13,20 and disagreements over the degree to which such skills should be learned during residency or deferred to fellowship, ${ }^{16,21,22}$ a scoping review is optimally suited to clarify important issues and competencies related to transcatheter training in cardiac surgery.

The objectives of this review are (1) to establish the scope of available literature describing the performance of transcatheter cardiovascular procedures, (2) to identify competencies that may be required by cardiac surgery residents learning to perform transcatheter procedures, and (3) to develop a preliminary list of competencies that may be considered for inclusion in a transcatheter cardiac surgery training curriculum.

\section{METHODS}

\section{Study Design and Search Strategy}

A scoping review was designed according to the Preferred Reporting Items for Systematic Reviews and Meta-Analyses Extension for Scoping Reviews. ${ }^{18}$ Information sources and coverage dates included MEDLINE
(1946 to April 1, 2020), Scopus (1970 to April 1, 2020), and ERIC (1966 to Apr 1, 2020). Relevant Medical Subject Heading terms and key words were compiled from target MEDLINE sources of evidence using the population (cardiac surgery trainees), concept (transcatheter competencies) and context (residency training) approach to designing a scoping review search strategy. ${ }^{17}$ The final, comprehensive MEDLINE search (Table E1) was then translated to Scopus and ERIC. No limitations were placed on publication type or year to retain the full extent of available evidence. Deduplication was performed using a simplified version of the Bramer method ${ }^{23}$ in EndNote X9 (Clarivate Analytics, Philadelphia, Pa).

\section{Screening Sources of Evidence}

Two authors screened the title and abstract of each source of evidence to identify those that would be suitable for full-text review. Any disagreements were resolved by consensus. Criteria for eligibility were (1) inclusion of cardiac surgery as a specialty, (2) description of a transcatheter procedure or procedures, and (3) empiric description of one or more competencies. Consistent with scoping review methodology, empiric descriptions of competencies were initially considered in an exploratory manner. Based on their usage in the literature, these were then defined as naming specific procedural steps, describing something using language such as "skill," "ability," "knowledge," "competency," or "behaviour" or otherwise implying that something is crucial to successfully perform the procedure or deliver care. Non-English records were excluded along with those having pediatric patients due to the subspecialized care required by this population.

\section{Data Charting and Synthesis}

In-depth review was performed to verify eligibility of the screened sources of evidence using the aforementioned criteria. Sources lacking online full-text availability were excluded at this stage. Data charting was conducted independently, documenting citation information, publication type, country (defined by first author affiliation), procedure(s) discussed and descriptions of competencies. Attempts were made to preserve the original wording of each competency, although simplifications were permitted in favor of conciseness, comprehensibility, and generalizability. Assumptions were made to ensure a common structure among all competencies, while similar items were grouped together to prevent redundancies while frequency counts were preserved. For example, "appropriate diagnostics" (from the multisocietal statements on transcatheter aortic ${ }^{24}$ and mitral $^{25}$ valve repair and replacement) and "knowledge of thoracic aortic pathology; its diagnosis" (from the clinical competence statement on thoracic endovascular aortic repair ${ }^{26}$ ) were all assumed to refer to the ability to diagnose pathologic conditions and therefore grouped as "diagnose structural heart and thoracic aortic disease" with a frequency count of 3 ( 1 for each relevant citation).

The authors participated in an iterative, inductive process to synthesize and further refine the list of identified competencies. Differences of opinion were addressed through group discussion until consensus was reached.

\section{RESULTS \\ Results of Search}

A total of 1456 sources of evidence were retrieved, including 1038 unique records. After title and abstract screening only 78 records remained for full-text review. Of these, 33 records were found to meet criteria for inclusion in the scoping review (Figure 1). The complete results of this scoping review are summarized in Figure 2.

\section{Scope of the Literature}

The earliest identified sources of evidence were published in 2006 (Table 1). ${ }^{27-40,42,44-49}$ Since then, there has been a steady, although nonlinear, increase in the 


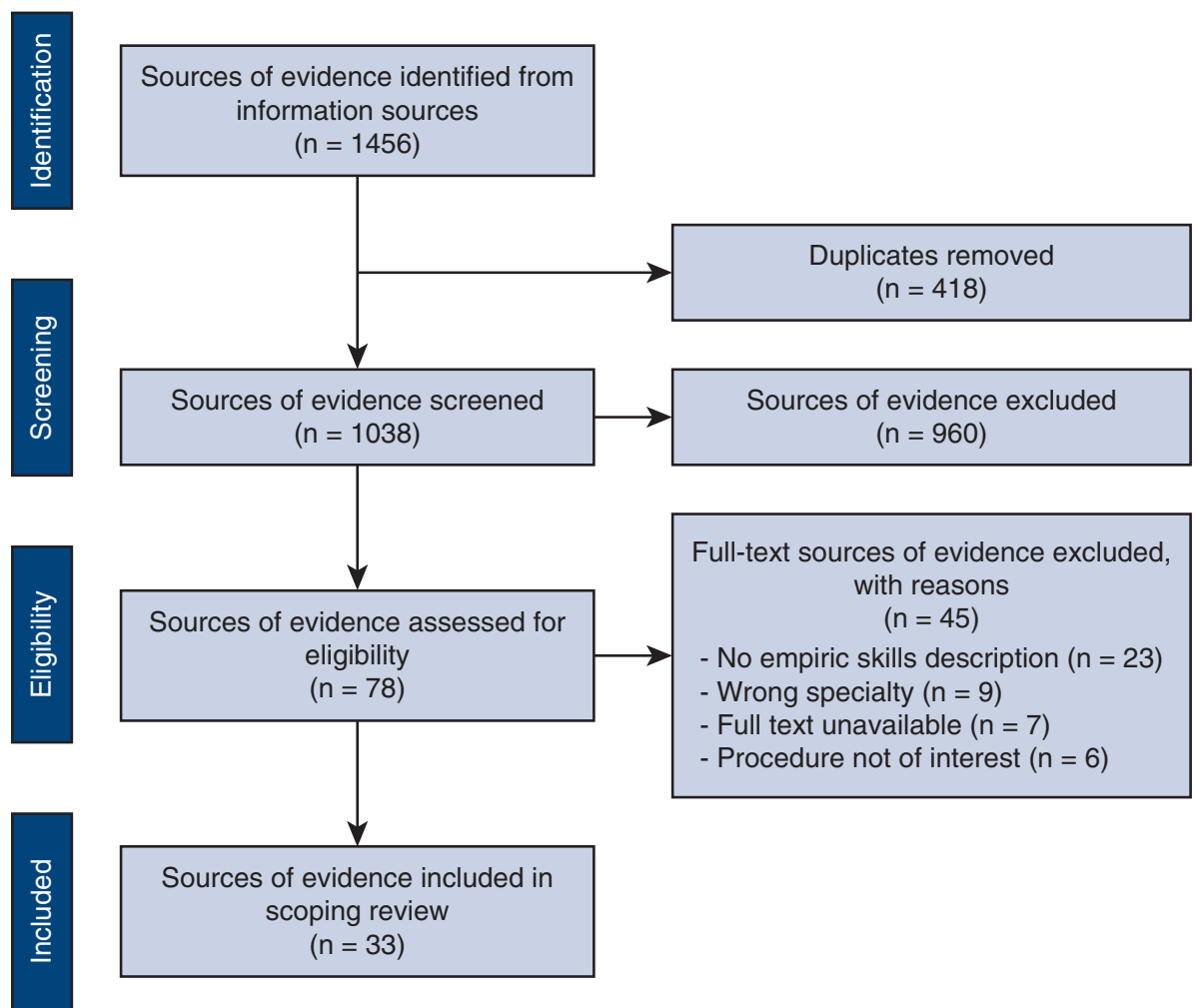

FIGURE 1. PRISMA-Scr diagram. A total of 1456 sources of evidence were retrieved using the search strategy. After deduplication, screening, and full-text review, there remained 33 sources of evidence included in this review.

number of publications, particularly from 2016 to 2020 , during which $60.6 \%(n=20)$ of identified records were published (Figure 3). Publication types consisted mainly of comparative studies $(30.3 \% ; \mathrm{n}=10)$ and societal statements $(24.2 \% ; \mathrm{n}=8)$ with a smaller proportion of surveys and opinion articles (both $15.2 \% ; \mathrm{n}=5$ ). North America contributed $75.8 \%$ of publications $(n=25)$, of which $80 \%(\mathrm{n}=20)$ were from the United States and $20 \%(\mathrm{n}=5)$ from Canada (Figure 4$)$.
In terms of the representation of specialties, cardiac surgery alone comprised $48.5 \%(n=16)$ of publications, equivalent to the number of combined cardiac surgery and cardiology publications. Collaboration between the 2 specialties was especially reflected in societal statements, all but one of which included members of cardiac surgical societies (such as the Canadian Society of Cardiac Surgeons, Society of Thoracic Surgeons, American Association for Thoracic Surgery or European Association

\section{A scoping review to identify competencies for transcatheter cardiovascular procedures}

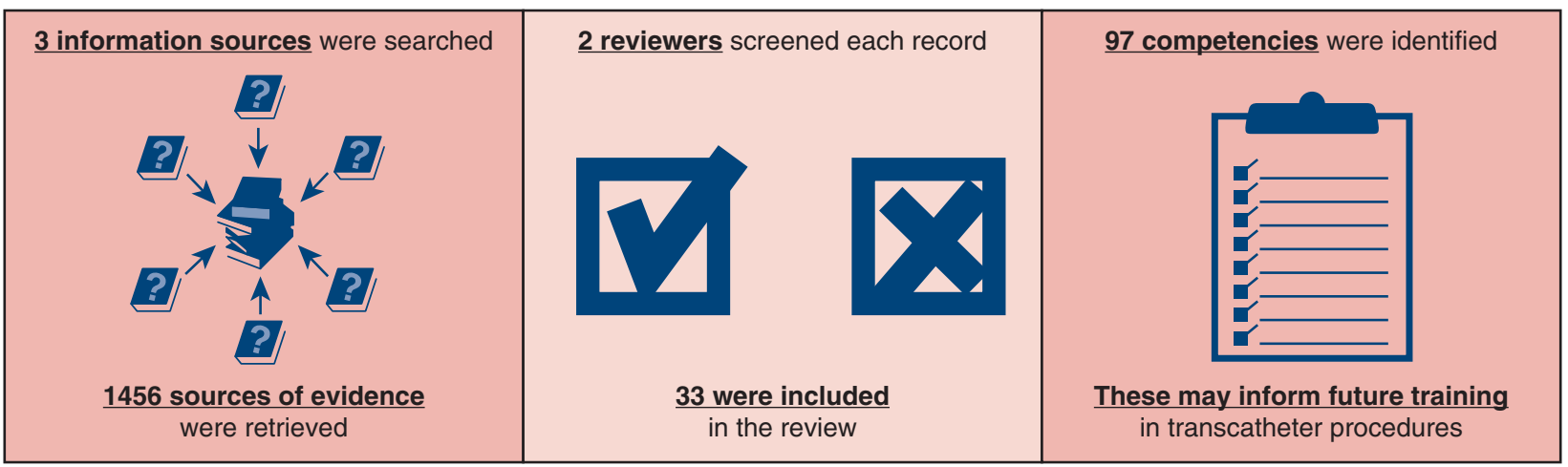

FIGURE 2. This scoping review has identified 97 competencies required to perform transcatheter cardiac surgery, with the goal of facilitating future training. 
TABLE 1. Characteristics of included sources of evidence

\begin{tabular}{|c|c|c|c|c|c|c|c|}
\hline No. & Authors & Year & $\begin{array}{l}\text { Publication } \\
\text { type }\end{array}$ & Country & Specialty & Procedure & $\begin{array}{c}\text { Competencies } \\
\text { identified, } \mathbf{n}\end{array}$ \\
\hline 1 & Alli et $\mathrm{al}^{27}$ & 2016 & Comparative study & US & Cardiac surgery, cardiology & TAVI & 1 \\
\hline 2 & Arai et $\mathrm{al}^{28}$ & 2016 & Comparative study & France & Cardiac surgery & TAVI & 2 \\
\hline 3 & Asgar et $\mathrm{al}^{29}$ & 2019 & Societal statement & Canada & Cardiac surgery, cardiology & TAVI & 9 \\
\hline 4 & Barbash et $\mathrm{al}^{30}$ & 2015 & Comparative study & Israel & Cardiac surgery, cardiology & TAVI & 8 \\
\hline 5 & Bavaria et $\mathrm{al}^{31}$ & 2019 & Societal statement & US & Cardiac surgery, cardiology & TAVI & 27 \\
\hline 6 & De Vecchi et al ${ }^{32}$ & 2018 & Comparative study & UK & Cardiac surgery, cardiology & Mitral & 3 \\
\hline 7 & $\begin{array}{l}\text { Gollmann-Tepekoylu } \\
{\text { et } \mathrm{al}^{33}}\end{array}$ & 2018 & Description of simulator & Austria & Cardiac surgery & Mitral & 9 \\
\hline 8 & Gomes et $\mathrm{al}^{34}$ & 2018 & Description of simulator & Brazil & Cardiac surgery & $\begin{array}{l}\text { TAVI } \\
\text { TEVAR }\end{array}$ & 3 \\
\hline 9 & Groves et $\mathrm{al}^{35}$ & 2014 & Comparative study & US & Cardiac surgery, cardiology & TAVI & 1 \\
\hline 10 & Hage et $\mathrm{al}^{22}$ & 2020 & Opinion & Canada & Cardiac surgery & TAVI & 17 \\
\hline 11 & Herrmann et al ${ }^{36}$ & 2010 & Survey & US & Cardiac surgery, cardiology & $\begin{array}{l}\text { TAVI } \\
\text { Mitral } \\
\text { Other }\end{array}$ & 12 \\
\hline 12 & Hodgson et $\mathrm{al}^{26}$ & 2006 & Societal statement & US & $\begin{array}{l}\text { Cardiac surgery, vascular } \\
\text { surgery, radiology }\end{array}$ & TEVAR & 24 \\
\hline 13 & Holmes et $\mathrm{al}^{37}$ & 2012 & Societal statement & US & Cardiac surgery, cardiology & TAVI & 28 \\
\hline 14 & Ikonomidis et $\mathrm{al}^{38}$ & 2016 & Survey & US & Cardiac surgery & $\begin{array}{l}\text { TEVAR } \\
\text { Other }\end{array}$ & 6 \\
\hline 15 & Indolfi et $\mathrm{al}^{39}$ & 2017 & Comparative study & Italy & Cardiac surgery, cardiology & TAVI & 3 \\
\hline 16 & Jilaihawi et $\mathrm{al}^{40}$ & 2010 & Comparative study & UK & Cardiac surgery & TAVI & 4 \\
\hline 17 & Juanda et $\mathrm{al}^{41}$ & 2016 & Survey & Canada & Cardiac surgery & $\begin{array}{l}\text { TAVI } \\
\text { Mitral } \\
\text { Other }\end{array}$ & 10 \\
\hline 18 & Lazar $^{21}$ & 2016 & Editorial & US & Cardiac surgery & $\begin{array}{l}\text { TAVI } \\
\text { TEVAR }\end{array}$ & 4 \\
\hline 19 & Minha et $\mathrm{al}^{42}$ & 2016 & Comparative study & US & Cardiac surgery, cardiology & TAVI & 5 \\
\hline 20 & Neely et $\mathrm{al}^{43}$ & 2014 & Narrative review & US & Cardiac surgery & TAVI & 20 \\
\hline 21 & Nguyen and George ${ }^{44}$ & 2015 & Opinion & US & Cardiac surgery & TAVI & 9 \\
\hline 22 & Nguyen et al ${ }^{16}$ & 2019 & Opinion & US & Cardiac surgery & $\begin{array}{l}\text { TAVI } \\
\text { Mitral } \\
\text { Other }\end{array}$ & 32 \\
\hline 23 & Pelletier et $\mathrm{a}^{20}$ & 2017 & Opinion & US & Cardiac surgery & $\begin{array}{l}\text { TAVI } \\
\text { TEVAR } \\
\text { Mitral } \\
\text { Other }\end{array}$ & 17 \\
\hline 24 & Ruiz et $\mathrm{al}^{45}$ & 2010 & Societal statement & US & Cardiac surgery, cardiology & $\begin{array}{l}\text { TAVI } \\
\text { Mitral } \\
\text { Other }\end{array}$ & 52 \\
\hline 25 & Tam et $\mathrm{al}^{13}$ & 2018 & Survey & Canada & Cardiac surgery & TAVI & 8 \\
\hline 26 & Tommaso et $\mathrm{al}^{24}$ & 2012 & Societal statement & US & Cardiac surgery, cardiology & $\begin{array}{l}\text { TAVI } \\
\text { TEVAR } \\
\text { Mitral }\end{array}$ & 33 \\
\hline 27 & Tommaso et $\mathrm{al}^{25}$ & 2014 & Societal statement & US & Cardiac surgery, cardiology & Mitral & 10 \\
\hline 28 & Vahanian et $\mathrm{al}^{46}$ & 2008 & Societal statement & France & Cardiac surgery, cardiology & TAVI & 28 \\
\hline
\end{tabular}


TABLE 1. Continued

\begin{tabular}{|c|c|c|c|c|c|c|c|}
\hline No. & Authors & Year & $\begin{array}{c}\text { Publication } \\
\text { type }\end{array}$ & Country & Specialty & Procedure & $\begin{array}{c}\text { Competencies } \\
\text { identified, } \mathbf{n}\end{array}$ \\
\hline 29 & $\begin{array}{c}\text { Vahidkhah and } \\
\text { Azadani }^{47}\end{array}$ & 2017 & Comparative study & US & Cardiac surgery, cardiology & TAVI & 1 \\
\hline 30 & Vardas et $\mathrm{al}^{14}$ & 2017 & Survey & US & Cardiac surgery & $\begin{array}{l}\text { TAVI } \\
\text { TEVAR } \\
\text { Mitral } \\
\text { Other }\end{array}$ & 6 \\
\hline 31 & Wassef et $\mathrm{al}^{48}$ & 2018 & Comparative study & Canada & Cardiac surgery, cardiology & TAVI & 5 \\
\hline 32 & Wheatley ${ }^{49}$ & 2019 & Editorial & US & Cardiac surgery & TAVI & 1 \\
\hline 33 & $\begin{array}{l}\text { Wheatley and } \\
\text { Diethrich }^{50}\end{array}$ & 2006 & Opinion & US & Cardiac surgery & $\begin{array}{l}\text { TEVAR } \\
\text { Other }\end{array}$ & 4 \\
\hline
\end{tabular}

"Mitral" indicates transcatheter mitral repair or replacement. TAVI, Transcatheter aortic valve implantation; TEVAR, thoracic endovascular aortic repair.

of Cardio-Thoracic Surgery) collaborating with members of interventional cardiology societies (such as the Canadian Association of Interventional Cardiology, Society for Cardiovascular Angiography and Interventions or European Association of Percutaneous Cardiovascular Interventions).

Transcatheter aortic valve implantation (TAVI) was by far the most described procedure. When considering only isolated procedures, a total of $54.5 \%(n=18)$ of sources of evidence described TAVI, followed by mitral valve interventions in $9.1 \%(\mathrm{n}=3)$ and thoracic endovascular aortic repair in $3.0 \%(\mathrm{n}=1)$. By comparison, when all procedure types are considered, $90.9 \%(n=30)$ of sources of evidence described TAVI, mitral valve interventions, or both.

\section{Competencies}

A total of 400 items, comprising 97 unique competencies, were identified from the literature (Table 2). The median frequency count per competency was 3 (interquartile range, 1-6). The most commonly identified competencies included obtaining vascular access and closure $(63.6 \%$ and $42.4 \%$ of included sources of evidence, respectively), procedural decision-making $(51.5 \%$ of included sources of evidence), and interpreting echocardiography (39.4\% of included sources of evidence). There were 29 competencies that were only identified from single sources of evidence; all other competencies were identified in at least 2 sources.

\section{DISCUSSION}

This scoping review provides an overview of the literature describing the performance of transcatheter cardiovascular procedures. The study objectives were successfully met, namely establishing the scope of available literature, identifying competencies required to perform the procedures, and developing a list of competencies for consideration in a training curriculum. By establishing the scope of the literature and clarifying the competencies that may be required by cardiac surgery residents learning to perform transcatheter procedures, we have established a suitable foundation to inform future evidence-based research. The growing number of publications-particularly in the past 5 years-and number

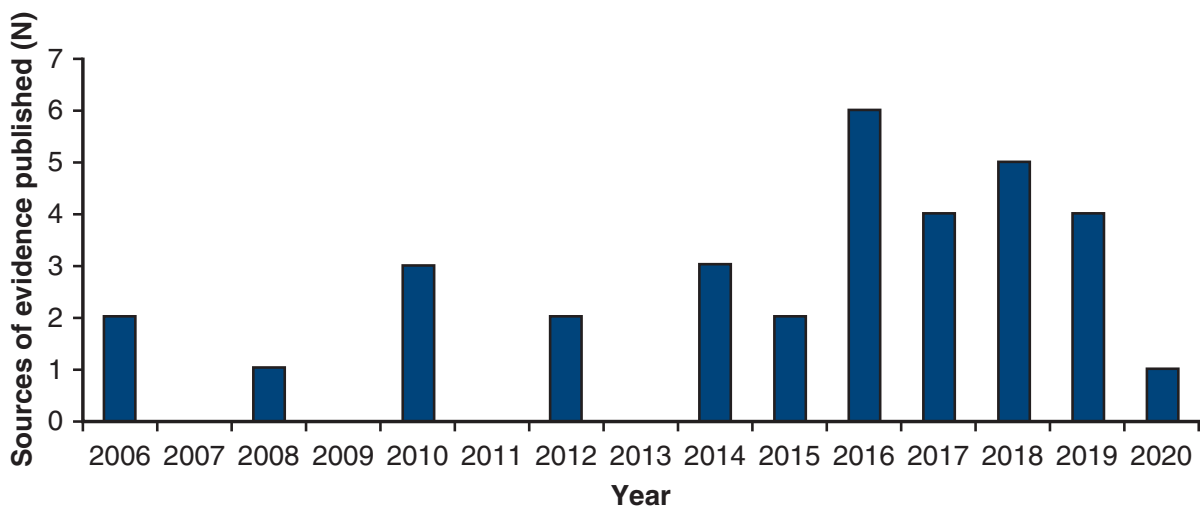

FIGURE 3. Sources of evidence published by year. There has been a steady, although nonlinear, increase in the number of yearly publications that were included in this review, particularly since 2016 . 


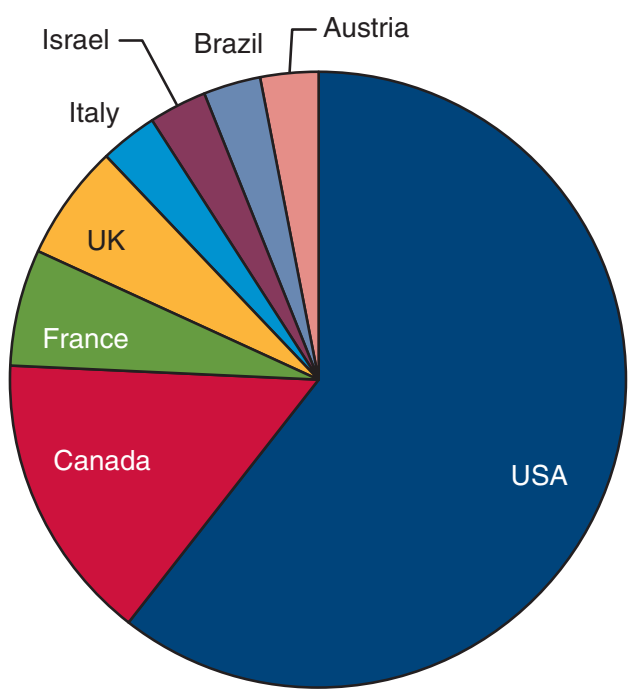

FIGURE 4. Sources of evidence published by country. The majority of included evidence was retrieved from North American sources, as defined by first author affiliation.

of comparative studies emphasizes the fact that this is a rapidly developing field. This is likely driven by the favorable clinical outcomes of randomized trials comparing transcatheter with traditional cardiac surgery. Considering the number of large, multicenter and multinational randomized trials that have compared TAVI with surgical aortic valve replacement, ${ }^{5-7,51-53}$ it is unsurprising that TAVI was the most frequently described procedure among the identified sources of evidence. The distribution of specialties among identified sources of evidence highlights the desire and initiative of cardiac surgeons to be involved in transcatheter procedures as well as the multidisciplinary nature of cardiac surgical practice, which in the clinical realm is embodied by the heart team concept. Cardiac surgeons should strive for continued involvement in all elements of transcatheter procedures in order to maintain their role in the treatment of structural heart and aortic disease.

The rapid growth of transcatheter techniques and desire to remain involved in the care of patients with structural heart or aortic disease has prompted surgeons to advocate for changes to training paradigms that would increase the focus on transcatheter training. ${ }^{16,22,50}$ Considering the vastly different nature of transcatheter and traditional cardiac surgery, however, few tangible changes have been made. This, coupled with conflicting opinions on the amount of transcatheter training that should occur during residency versus fellowship, has led to ambiguous expectations regarding the level of transcatheter competency that a resident should possess by the end of their training. Moreover, the evidence is clear that simply increasing the number of transcatheter rotations is unlikely to meet the needs of most residents. ${ }^{13,14,41}$ Instead clear, actionable, and evidence-based educational interventions are required. For example, rather than being told to focus on "wire skills," the results of this review could be used to provide residents with more clearly delineated goals such as obtaining vascular access, performing a wire exchange, crossing a stenotic aortic valve and so forth according to their needs and stage of training. The advantage of this approach is that it is informed by the literature rather than operator experience or clinical gestalt. While we identified several sources of evidence describing competencies required for transcatheter cardiovascular procedures, until now no group has attempted to synthesize this evidence in a comprehensive manner with cardiac surgery residents in mind. Indeed, we only identified one relevant review article, which was a narrative review by Neely and colleagues in $2014 .{ }^{43}$ As part of their review, they discussed new approaches to cardiac surgery, including percutaneous valve interventions. However they used a more general approach by describing the procedures and results from early trials without the overt intent of identifying learning goals. We hope that the competencies we have identified will prove useful for surgeon-educators who are designing interventions to teach transcatheter procedures to cardiac surgery trainees.

The results of this review, however, should not be interpreted as a reference for the competencies that cardiac surgeons absolutely must be require to perform transcatheter procedures. Indeed, it may not be practical to introduce such an extensive list of objectives when designing specific interventions for a transcatheter curriculum. Rather, the intent has been to summarize the entirety of available evidence to identify all of the competencies that a cardiac surgeon in-training may potentially attain assuming no constraints of time, resources, or expertise. This approach is guided by the Kern model of curricular development, which first requires the identification of a problem and a general needs assessment, after which more targeted needs assessments may inform the selection of educational goals and interventions specific to a group of learners in a particular setting or environment. ${ }^{54}$ As the problem of transcatheter skills acquisition by cardiac surgery trainees is well established, ${ }^{13-16}$ the identified competencies represent rather the conclusion of this first step in curricular design, namely a general needs assessment. While it is possible - and even likely - that some of the identified competencies may not ultimately be required by cardiac surgery residents, educators may still find it beneficial to consider the gaps between what is currently taught to residents at their institution and what may potentially be taught in an ideal setting. The results of this review can therefore inform future stages of curricular development including targeted needs assessments and developing, 
TABLE 2. Identified competencies with frequency counts and relative proportion of included sources of evidence

\begin{tabular}{|c|c|c|c|}
\hline Competency & $\begin{array}{l}\text { Frequency, } \\
\mathbf{n}\end{array}$ & $\begin{array}{l}\text { Proportion, } \\
\%\end{array}$ & $\begin{array}{c}\text { Sources of evidence } \\
\text { (as numbered in Table } 1 \text { ) }\end{array}$ \\
\hline General knowledge and skill & 8 & 24.2 & \\
\hline Diagnose structural heart and thoracic aortic disease & 3 & 9.1 & $5,12,26$ \\
\hline $\begin{array}{l}\text { Understand the etiology, pathophysiology, and natural history of } \\
\text { structural heart and aortic disease }\end{array}$ & 5 & 15.2 & $5,12,22,24,26$ \\
\hline $\begin{array}{l}\text { Understand the hemodynamic consequences of treated and untreated } \\
\text { structural heart disease }\end{array}$ & 6 & 18.2 & $5,7,15,22,24,26$ \\
\hline Recommend optimal medical therapy & 3 & 9.1 & $5,24,26$ \\
\hline Understand the relevant anatomy & 3 & 9.1 & $22,24,27$ \\
\hline Take a history & 1 & 3.0 & 24 \\
\hline Perform a physical examination & 1 & 3.0 & 24 \\
\hline Communication and collaboration & 11 & 33.3 & \\
\hline Collaborate with multidisciplinary team members & 11 & 33.3 & $3,5,10,13,20,22-24,26-28$ \\
\hline Interact with patients and their families & 3 & 9.1 & $13,24,26$ \\
\hline Participate in registries and outcome studies & 2 & 6.1 & 24,26 \\
\hline Perioperative care & 13 & 39.4 & \\
\hline Evaluate a patient and optimize them before the procedure & 9 & 27.3 & $5,10,21-24,26-28$ \\
\hline Manage coexisting conditions & 1 & 3.0 & 13 \\
\hline Develop a preprocedural plan for the case & 3 & 9.1 & $8,12,22$ \\
\hline Provide postprocedural care & 8 & 24.2 & $3,5,21,22,24,26-28$ \\
\hline Provide follow-up & 7 & 21.2 & $5,12,13,23,24,26,27$ \\
\hline Patient selection & 14 & 42.4 & \\
\hline $\begin{array}{l}\text { Know, interpret, and apply the outcomes of clinical trials to decide the } \\
\text { optimal interventional strategy }\end{array}$ & 6 & 18.2 & $5,12,13,22,24,26$ \\
\hline Perform a preoperative risk assessment & 7 & 21.2 & $3,4,13,20,26-28$ \\
\hline $\begin{array}{l}\text { Select candidates for transcatheter procedures using clinical practice } \\
\text { guidelines, indications, and contraindications }\end{array}$ & 10 & 30.3 & $10,12,20-24,26-28$ \\
\hline Imaging & 18 & 54.5 & \\
\hline Echocardiography & 14 & 42.4 & \\
\hline Acquire echocardiography & 2 & 6.1 & 11,22 \\
\hline Interpret echocardiography & 13 & 39.4 & $3,5,7,10,13,16,20,22,24,26-28,31$ \\
\hline Fluoroscopy & 10 & 30.3 & \\
\hline Acquire fluoroscopic images & 6 & 18.2 & $5,10,12,22,23,28$ \\
\hline Interpret fluoroscopic images & 6 & 18.2 & $4,8,12,22,24,28$ \\
\hline Interpret coronary angiography & 2 & 6.1 & 3,28 \\
\hline Computed tomography & 12 & 36.4 & \\
\hline Interpret computed tomographic scans & 12 & 36.4 & $3-5,8,10,12,13,20,22,24,26,28$ \\
\hline Magnetic resonance imaging & 4 & 12.1 & \\
\hline Interpret magnetic resonance imaging & 4 & 12.1 & $13,22,24,28$ \\
\hline $\begin{array}{l}\text { Cardiac catheterization laboratory and hybrid operating room } \\
\text { environment }\end{array}$ & 10 & 30.3 & \\
\hline Understand radiation safety & 3 & 9.1 & $5,10,26$ \\
\hline Interpret hemodynamics in the cardiac catheterization laboratory & 4 & 12.1 & $5,24,26,28$ \\
\hline $\begin{array}{l}\text { Know how to use relevant equipment in the cardiac catheterization } \\
\text { laboratory or hybrid operating room, including the C-arm and } \\
\text { contrast injection systems }\end{array}$ & 8 & 24.2 & $10,12,22,23,25,26,28,30$ \\
\hline Understand how to use contrast agents & 2 & 6.1 & 5,26 \\
\hline Work in a sterile environment & 1 & 3.0 & 28 \\
\hline Vascular access & 23 & 69.7 & \\
\hline Insert a central venous line or Swan-Ganz catheter & 2 & 6.1 & 10,18 \\
\hline Insert an arterial line & 2 & 6.1 & 10,18 \\
\hline Obtain vascular access using surgical or percutaneous approach & 21 & 63.6 & $1-3,5,7,10,12,13,17,18,20-26,28,30,31,33$ \\
\hline $\begin{array}{l}\text { Achieve vascular closure by direct repair or by using a vascular } \\
\text { closure device }\end{array}$ & 14 & 42.4 & $3-5,7,12,13,19,20,22-26,28$ \\
\hline
\end{tabular}




\begin{tabular}{|c|c|c|c|}
\hline Competency & $\begin{array}{l}\text { Frequency, } \\
\quad \mathbf{n}\end{array}$ & $\begin{array}{l}\text { Proportion, } \\
\%\end{array}$ & $\begin{array}{c}\text { Sources of evidence } \\
\text { (as numbered in Table 1) }\end{array}$ \\
\hline Access the heart and great vessels via transthoracic approaches & 4 & 12.1 & $13,20,21,28$ \\
\hline Select an approach & 5 & 15.2 & $2,13,20,23,30$ \\
\hline Dilate access vessel under fluoroscopic vision & 1 & 3.0 & 13 \\
\hline Perform surgical procedures on the LV apex & 4 & 12.1 & $13,20,26,28$ \\
\hline Place purse string sutures & 2 & 6.1 & 13,28 \\
\hline Wire management and manipulation & 15 & 45.5 & \\
\hline Select wires, catheters, and sheaths & 6 & 18.2 & $4,10,12,21,22,24$ \\
\hline Insert wires, catheters and sheaths & 6 & 18.2 & $13,20-23,28$ \\
\hline $\begin{array}{l}\text { Navigate vascular anatomic structures by manipulating wires and } \\
\text { catheters }\end{array}$ & 7 & 21.2 & $5,7,12,23-26$ \\
\hline Manage brachial-femoral wires & 1 & 3.0 & 33 \\
\hline Perform wire exchange & 1 & 3.0 & 13 \\
\hline Prostheses & 21 & & \\
\hline Perform size measurements for transcatheter prostheses & 9 & 27.3 & $3,4,12,13,15,16,20,22,30$ \\
\hline Select a transcatheter prosthesis & 6 & 18.2 & $4,6,10,12,15,23$ \\
\hline Deliver a transcatheter prosthesis & 8 & 24.2 & $7,10,12,13,19,20,22,31$ \\
\hline Position a transcatheter prosthesis & 10 & 30.3 & $6,7,9,13,16,20,22,23,28,29$ \\
\hline Deploy a transcatheter prosthesis & 12 & 36.4 & $7,12,13,19-25,28,31$ \\
\hline Pacing & 6 & 18.2 & \\
\hline Insert a temporary pacing device (wire or epicardial lead) & 3 & 9.1 & $13,20,25$ \\
\hline Perform rapid ventricular pacing & 5 & 15.2 & $13,19,20,24,28$ \\
\hline Cardiac surgery & 9 & 27.3 & \\
\hline Develop surgical experience with valve of interest & 3 & 9.1 & $24,27,28$ \\
\hline Insert and manage peripheral mechanical circulatory support & 5 & 15.2 & $5,10,13,26,28$ \\
\hline Insert cannulae for initiating cardiopulmonary bypass & 1 & 3.0 & 18 \\
\hline Perform a frozen elephant trunk & 1 & 3.0 & 33 \\
\hline Transcatheter interventions & 25 & 75.8 & \\
\hline $\begin{array}{l}\text { Make decisions during the procedure including anticipating, } \\
\text { recognizing, and treating procedural complications }\end{array}$ & 17 & 51.5 & $4-6,12,13,16,20-24,26-28,31,33$ \\
\hline Perform intravascular ultrasonography & 1 & 3.0 & 12 \\
\hline Use cerebral embolic protection & 1 & 3.0 & 22 \\
\hline Perform intravascular snaring and retrieval & 2 & 6.1 & 5,12 \\
\hline Perform coil embolization & 1 & 3.0 & 12 \\
\hline Perform side-branch angioplasty and stenting & 1 & 3.0 & 12 \\
\hline Valvular cardiac interventions & 12 & 36.4 & \\
\hline Perform transcatheter pulmonary valve implantation (TPVI) & 1 & 3.0 & 24 \\
\hline Cross the stenotic aortic valve in antegrade or retrograde fashion & 7 & 21.2 & $13,20,22-25,28$ \\
\hline Perform paravalvular leak closure & 3 & 9.1 & $5,11,24$ \\
\hline $\begin{array}{l}\text { Perform balloon aortic, mitral, tricuspid, or pulmonary } \\
\text { valvuloplasty }\end{array}$ & 11 & 33.3 & $5,11,13,17,19,20,22,24,25,26,28$ \\
\hline Nonvalvular cardiac interventions & 10 & 30.3 & \\
\hline Perform transhepatic access & 1 & 3.0 & 24 \\
\hline Perform balloon pericardiotomy & 1 & 3.0 & 24 \\
\hline Perform ventricular pseudoaneurysm closure & 1 & 3.0 & 24 \\
\hline Perform endovascular endoleak closure & 1 & 3.0 & 24 \\
\hline Perform aortic pseudoaneurysm closure & 1 & 3.0 & 24 \\
\hline Perform angioplasty and stenting for coarctation of the aorta & 1 & 3.0 & 24 \\
\hline $\begin{array}{l}\text { Perform angioplasty and stenting of surgical conduits, baffles and } \\
\text { homografts }\end{array}$ & 1 & 3.0 & 24 \\
\hline $\begin{array}{l}\text { Perform angioplasty and stenting of interatrial septum and Fontan } \\
\text { fenestrations }\end{array}$ & 1 & 3.0 & 24 \\
\hline Perform coronary angiography & 6 & 18.2 & $5,10,17,22,26,30$ \\
\hline Perform PCI & 4 & 12.1 & $5,10,17,22$ \\
\hline
\end{tabular}




\begin{tabular}{|c|c|c|c|}
\hline Competency & $\begin{array}{l}\text { Frequency, } \\
\text { n }\end{array}$ & $\begin{array}{l}\text { Proportion, } \\
\%\end{array}$ & $\begin{array}{c}\text { Sources of evidence } \\
\text { (as numbered in Table 1) }\end{array}$ \\
\hline Perform transseptal puncture & 6 & 18.2 & $7,11,22,24,26,32$ \\
\hline Perform transseptal left heart catheterization & 1 & 3.0 & 24 \\
\hline Perform ASD closure & 3 & 9.1 & $11,24,30$ \\
\hline Perform pulmonary vein stenting & 2 & 6.1 & 11,24 \\
\hline Perform VSD closure & 2 & 6.1 & 11,24 \\
\hline Access the coronary sinus & 2 & 6.1 & 24,26 \\
\hline Perform septal ablation & 2 & 6.1 & 11,24 \\
\hline Perform PFO closure & 2 & 6.1 & 11,24 \\
\hline Perform PDA closure & 2 & 6.1 & 11,24 \\
\hline Perform LAA exclusion & 2 & 6.1 & 11,24 \\
\hline Perform PA stenting & 2 & 6.1 & 24,26 \\
\hline Perform coronary fistula embolization & 2 & 6.1 & 11,24 \\
\hline Vascular interventions & 6 & 18.2 & \\
\hline $\begin{array}{l}\text { Perform brachiocephalic transposition or extra-anatomic } \\
\text { revascularizations }\end{array}$ & 1 & 3.0 & 12 \\
\hline Perform carotid artery stenting & 1 & 3.0 & 14 \\
\hline Perform endovascular treatment of aortoiliac disease & 1 & 3.0 & 14 \\
\hline Perform endovascular treatment of great vessel occlusive disease & 1 & 3.0 & 14 \\
\hline Perform endovascular treatment of mesenteric vascular disease & 1 & 3.0 & 14 \\
\hline Perform percutaneous embolectomy/thrombectomy & 1 & 3.0 & 17 \\
\hline Perform interventions for PVD & 4 & 12.1 & $5,14,17,26$ \\
\hline Perform peripheral angiography & 2 & 6.1 & 17,26 \\
\hline Perform EVAR & 4 & 12.1 & $5,14,17,26$ \\
\hline Perform balloon angioplasty & 2 & 6.1 & 17,23 \\
\hline
\end{tabular}

$L V$, Left ventricular; $P C I$, percutaneous coronary intervention; $A S D$, atrial septal defect; $V S D$, ventricular septal defect; $p F O$, Patent foramen ovale; $P D A$, patent ductus arteriosus; $L A A$, left atrial appendage; $P A$, pulmonary artery; $P V D$, peripheral vascular disease; $E V A R$, endovascular abdominal aortic aneurysm repair.

implementing then refining educational interventions according to the identified needs.

Strengths of this review include the number of information sources searched, systematic approach to collect sources of evidence, methodology facilitating the inclusion of broad publication types, and iterative approach to compile the final list of competencies that addresses an important gap in the literature. This review has several limitations. While frequency count was included as a preliminary indication of relative importance (since more frequently referenced competencies would presumably hold greater weight), it may favor easily described competencies at the expense of those that are more subtle. Furthermore, the relative importance of a given competency may evolve depending on a resident's stage of training and career goals. We attempted to account for this by including individuals from diverse backgrounds as a quality control method while compiling the list of competencies, however a more rigorous approach-such as by confirming the relevance of these competencies with subject matter experts-is required to refine this list further and will be the focus of an upcoming Delphi consensus study. Limiting the eligibility criteria to English language only may have resulted in an inadvertent geographic bias producing a disproportionate number of North American publications. While this limits the generalizability of our review, it is unlikely that broader inclusion criteria would have produced vastly different results-particularly regarding the competencies that were identified - as the procedures themselves remain unchanged regardless of geographic location.

\section{CONCLUSIONS}

Literature on performing transcatheter cardiovascular procedures is available from a multitude of sources and origins. Information obtained from these sources of evidence may be useful for teaching residents to perform transcatheter procedures. The identified competencies will form the basis of future work prioritizing those that are considered fundamental for learning to perform transcatheter cardiovascular procedures.

\section{Conflict of Interest Statement}

The authors reported no conflicts of interest.

The Journal policy requires editors and reviewers to disclose conflicts of interest and to decline handling or reviewing manuscripts for which they may have a conflict of interest. The editors and reviewers of this article have no conflicts of interest.

\section{References}

1. Hiratska L, Bakris G, Beckman J, Bersin R, Carr V. 2010 ACCF/AHA/AATS/ ACR/ASA/SCA/SCAI/SIR/STS/SVM guidelines for the diagnosis and 
management of patients with thoracic aortic disease a report of the American College of Cardiology Foundation/American Heart Association task force on practice guidelines, American Association for Thoracic Surgery, American College of Radiology, American Stroke Association, Society of Cardiovascular Anesthesiologists, Society for Cardiovascular Angiography and Interventions, Society of Interventional Radiology, Society of Thoracic Surgeons, and Society for Vascular Medicine. Circulation. 2010;121:e266-369.

2. Erbel R, Aboyans V, Boileau C, Bossone E, Bartolomeo R. 2014 ESC guidelines on the diagnosis and treatment of aortic diseases: document covering acute and chronic aortic diseases of the thoracic and abdominal aorta of the adult. The task force for the diagnosis and treatment of aortic diseases of the European Society of Cardiology (ESC). Eur Heart J. 2014;35:2873-926.

3. Appoo JJ, Bozinovski J, Chu MWA, El-Hamamsy I, Forbes TL, Moon M, et al. Canadian Cardiovascular Society/Canadian Society of Cardiac Surgeons/ Canadian Society for Vascular Surgery joint position statement on open and endovascular surgery for thoracic aortic disease. Can J Cardiol. 2016;32: 703-13.

4. Riambau V, Böckler D, Cao P, Chiesa R, Coppi G. Management of descending thoracic aorta diseases: clinical practice guidelines of the European Society for Vascular Surgery (ESVS). Eur J Vasc Endovasc Surg. 2017;53:4-52.

5. Mack MJ, Leon MB, Smith CR, Miller DC, Moses JW, Tuzcu EM, et al. 5-year outcomes of transcatheter aortic valve replacement or surgical aortic valve replacement for high surgical risk patients with aortic stenosis (PARTNER 1): a randomised controlled trial. Lancet. 2015;385:2477-84.

6. Reardon MJ, Van Mieghem NM, Popma JJ, Kleiman NS, Søndergaard L, Mumtaz M, et al. Surgical or transcatheter aortic-valve replacement in intermediate-risk patients. N Engl J Med. 2017;376:1321-31.

7. Gleason TG, Reardon MJ, Popma JJ, Deeb GM, Yakubov SJ, Lee JS, et al. 5-year outcomes of self-expanding transcatheter versus surgical aortic valve replacement in high-risk patients. J Am Coll Cardiol. 2018;72:2687-96.

8. Leon MB, Smith CR, Mack MJ, Makkar RR, Svensson LG, Kodali SK, et al. Transcatheter or surgical aortic-valve replacement in intermediate-risk patients. N Engl J Med. 2016;374:1609-20.

9. Reardon M, Thourani V. Racing to the rubicon. J Thorac Cardiovasc Surg. 2018; 155:1457-8.

10. Stone GW, Lindenfeld JA, Abraham WT, Kar S, Lim DS, Mishell JM, et al. Transcatheter mitral-valve repair in patients with heart failure. $N$ Engl J Med. 2018:379:2307-18.

11. Obadia JF, Messika-Zeitoun D, Leurent G, Iung B, Bonnet G, Piriou N, et al. Percutaneous repair or medical treatment for secondary mitral regurgitation. $N$ Engl J Med. 2018;379:2297-306.

12. Royal College of Physicians and Surgeons of Canada. Cardiac Surgery Training Experiences. Ottawa, Canada: Royal College of Physicians and Surgeons of Canada; 2017.

13. Tam DY, Makhdoum A, Ouzounian M, Wijeysundera HC, Cohen GN, Fremes SE. The state of transcatheter aortic valve implantation training in Canadian cardiac surgery residency programs. Can J Surg. 2018;61:418-23.

14. Vardas PN, Stefanescu Schmidt AC, Lou X, Goldstone AB, Pattakos G, Fiedler AG, et al. Current status of endovascular training for cardiothoracic surgery residents in the United States. Ann Thorac Surg. 2017;104:1748-54.

15. Chu D, Vaporciyan AA, Iannettoni MD, Ikonomidis JS, Odell DD, Shemin RJ, et al. Are there gaps in current thoracic surgery residency training programs? Ann Thorac Surg. 2016;101:2350-5.

16. Nguyen TC, Tang GHL, Nguyen S, Forcillo J, George I, Kaneko T, et al. The train has left: can surgeons still get a ticket to treat structural heart disease? J Thorac Cardiovasc Surg. 2019;157:2369-76.e2.

17. Munn Z, Peters MDJ, Stern C, Tufanaru C, McArthur A, Aromataris E. Systematic review or scoping review? Guidance for authors when choosing between a systematic or scoping review approach. BMC Med Res Methodol. 2018;18:1-7.

18. Tricco AC, Lillie E, Zarin W, O’Brien KK, Colquhoun H, Levac D, et al. PRISMA extension for scoping reviews (PRISMA-ScR): checklist and explanation. Ann Intern Med. 2018;169:467-73.

19. Bavaria JE, Prager RL, Naunheim KS, Allen MS, Higgins RSD, Thourani VH, et al. Surgeon involvement in transcatheter aortic valve replacement in the United States: A 2016 Society of Thoracic Surgeons Survey. Ann Thorac Surg. 2017; 104:1088-93.

20. Pelletier MP, Kaneko T, Peterson MD, Thourani VH. From sutures to wires: the evolving necessities of cardiac surgery training. J Thorac Cardiovasc Surg. 2017; 154:990-3.

21. Lazar HL. What is the best method for cardiac surgeons to acquire catheter-based interventional skills? Can J Cardiol. 2016;32:289-90.
22. Hage A, Hage F, Chu MWA. Cardiac surgery residency and transcatheter aortic valve replacement: "what happened to my aortic valve replacement?" J Thorac Cardiovasc Surg. 2020;159:215-7.

23. Bramer WM, Giustini D, de Jonge GB, Holland L, Bekhuis T. De-duplication of database search results for systematic reviews in EndNote. J Med Libr Assoc. 2016;104:240-3.

24. Tommaso CL, 3rd Bolman RM, Feldman T, Bavaria J, Acker MA, Aldea G, et al. Multisociety (AATS, ACCF, SCAI, and STS) expert consensus statement: operator and institutional requirements for transcatheter valve repair and replacement, Part 1: transcatheter aortic valve replacement. Ann Thorac Surg. 2012; 93:2093-110.

25. Tommaso CL, Fullerton DA, Feldman T, Dean LS, Hijazi ZM, Horlick E, et al. SCAI/AATS/ACC/STS operator and institutional requirements for transcatheter valve repair and replacement. Part II. mitral valve. J Am Coll Cardiol. 2014;64: 1515-26.

26. Hodgson KJ, Matsumura JS, Ascher E, Dake MD, Sacks D, Krol K, et al. Clinical competence statement on thoracic endovascular aortic repair (TEVAR)-multispecialty consensus recommendations. A Report of the SVS/SIR/SCAI/SVMB writing committee to develop a clinical competence standard for TEVAR. $J$ Vasc Surg. 2006;43:858-62.

27. Alli O, Rihal CS, Suri RM, Greason KL, Waksman R, Minha S, et al. Learning curves for transfemoral transcatheter aortic valve replacement in the PARTNER-I trial: technical performance. Catheter Cardiovasc Interv. 2016; 87:154-62.

28. Arai T, Romano M, Lefevre T, Hovasse T, Bouvier E, Morice MC, et al. Impact of procedural volume on outcome optimization in transaortic transcatheter aortic valve implantation. Int J Cardiol. 2016;223:292-6.

29. Asgar AW, Ouzounian M, Adams C, Afilalo J, Fremes S, Lauck S, et al. 2019 Canadian Cardiovascular Society position statement for transcatheter aortic valve implantation. Can J Cardiol. 2019;35:1437-48.

30. Barbash IM, Barbanti M, Webb J, Molina-Martin De Nicolas J, Abramowitz Y, Latib A, et al. Comparison of vascular closure devices for access site closure after transfemoral aortic valve implantation. Eur Heart J. 2015;36:3370-9.

31. Bavaria JE, Tommaso CL, Brindis RG, Carroll JD, Deeb GM, Feldman TE, et al. 2018 AATS/ACC/SCAI/STS expert consensus systems of care document: operator and institutional recommendations and requirements for transcatheter aortic valve replacement: a joint report of the American Association for Thoracic Surgery, American College of of Cardiology, Society for Cardiovascular Angiography and Interventions, and Society of Thoracic Surgeons. Catheter Cardiovasc Interv. 2019;93:E153-84.

32. De Vecchi A, Marlevi D, Nordsletten DA, Ntalas I, Leipsic J, Bapat V, et al. Left ventricular outflow obstruction predicts increase in systolic pressure gradients and blood residence time after transcatheter mitral valve replacement. Sci Rep. 2018;8:15540.

33. Gollmann-Tepekoylu C, Holfeld J, Polzl G, Metzler B, Hintringer F, Adukauskaite A, et al. Beating heart porcine high-fidelity simulator for the training of edge-to-edge mitral valve repair. Multimed Man Cardiothorac Surg. 2018;16:16.

34. Gomes EN, Dias RR, Rocha BA, Santiago JAD, Dinato FJS, Saadi EK, et al. Use of $3 \mathrm{D}$ printing in preoperative planning and training for aortic endovascular repair and aortic valve disease. Braz J Cardiovasc Surg. 2018;33:490-5.

35. Groves EM, Falahatpisheh A, Su JL, Kheradvar A. The effects of positioning of transcatheter aortic valves on fluid dynamics of the aortic root. ASAIO J. 2014;60: 545-52.

36. Herrmann HC, Baxter S, Ruiz CE, Feldman TE, Hijazi ZM, Disease SC on SH. Results of the Society of Cardiac Angiography and Interventions survey of physicians and training directors on procedures for structural and valvular heart disease. Catheter Cardiovasc Interv. 2010;76:E106-10.

37. Holmes DR Jr, Mack MJ, Kaul S, Agnihotri A, Alexander KP, Bailey SR, et al. 2012 ACCF/AATS/SCAI/STS expert consensus document on transcatheter aortic valve replacement. J Am Coll Cardiol. 2012;59:1200-54.

38. Ikonomidis JS, Ad N, Aldea GS, Argenziano M, Galloway AC, Hagberg RC, et al. Vascular operations performed by cardiothoracic surgeons: the Society of Thoracic Surgeons survey. Ann Thorac Surg. 2016;102:589-92.

39. Indolfi C, Sabatino J, De Rosa S, Mongiardo A, Ricci P, Spaccarotella C. Description and validation of TAVIApp: a novel mobile application for support of physicians in the management of aortic stenosis-management of aortic stenosis with TAVIApp. Biomed Res Int. 2017;2017:9027597.

40. Jilaihawi H, Chin D, Spyt T, Jeilan M, Vasa-Nicotera M, Bence J, et al. Prosthesis-patient mismatch after transcatheter aortic valve implantation with the Medtronic-Corevalve bioprosthesis. Eur Heart J. 2010;31:857-64. 
41. Juanda N, Chan V, Chan R, Rubens FD. Catheter-based educational experiences: a canadian survey of current residents and recent graduates in cardiac surgery. Can J Cardiol. 2016;32:391-4.

42. Minha S, Waksman R, Satler LP, Torguson R, Alli O, Rihal CS, et al. Learning curves for transfemoral transcatheter aortic valve replacement in the PARTNER-I trial: success and safety. Catheter Cardiovasc Interv. 2016;87: 165-75.

43. Neely RC, Leacche M, Byrne CR, Norman AV, Byrne JG. New approaches to cardiovascular surgery. Curr Probl Cardiol. 2014;39:427-66.

44. Nguyen TC, George I. Beyond the hammer: the future of cardiothoracic surgery, J Thorac Cardiovasc Surg. 2015;149:675-7.

45. Ruiz CE, Feldman TE, Hijazi ZM, Holmes DR Jr, Webb JG, Tuzcu EM, et al. Interventional fellowship in structural and congenital heart disease for adults. Catheter Cardiovasc Interv. 2010;76:E90-105.

46. Vahanian A, Alfieri OR, Al-Attar N, Antunes MJ, Bax J, Cormier B, et al. Transcatheter valve implantation for patients with aortic stenosis: a position statement from the European Association of Cardio-Thoracic Surgery (EACTS) and the European Society of Cardiology (ESC), in collaboration with the European Association of Percu. Eur J Cardiothorac Surg. 2008;34:1-8.

47. Vahidkhah K, Azadani AN. Supra-annular valve-in-valve implantation reduces blood stasis on the transcatheter aortic valve leaflets. J Biomech. 2017; 58:114-22.

48. Wassef AWA, Rodes-Cabau J, Liu Y, Webb JG, Barbanti M, Munoz-Garcia AJ, et al. The learning curve and annual procedure volume standards for optimum outcomes of transcatheter aortic valve replacement: findings from an international registry. Jacc Cardiovasc Interv. 2018;11:1669-79.

49. Wheatley GH. Commentary: all aboard the transcatheter express-road map for surgeons to develop expertise in catheter-based treatment of structural heart disease. J Thorac Cardiovasc Surg. 2019;157:2377-8.

50. Wheatley GH, Diethrich EB. How to retrain the cardiothoracic surgeon. Interact Cardiovasc Thorac Surg. 2006;5:236-7.

51. Mack MJ, Leon MB, Thourani VH, Makkar R, Kodali SK, Russo M, et al. Transcatheter aortic-valve replacement with a balloon-expandable valve in low-risk patients. N Engl J Med. 2019;380:1695-705.

52. Popma JJ, Michael Deeb G, Yakubov SJ, Mumtaz M, Gada H, O’Hair D, et al Transcatheter aortic-valve replacement with a self-expanding valve in low-risk patients. N Engl J Med. 2019;380:1706-15.

53. Thyregod HGH, Thlemann N, Jørgensen TH, Nissen H, Kjeldsen BJ, Petursson P et al. Five-year clinical and echocardiographic outcomes from the notion randomized clinical trial in patients at lower surgical risk. Circulation. 2019;139:2714-23.

54. David K, Patricia T, Mark H. Curriculum Development for Medical Education: A Six-Step Approach. 2nd ed. Baltimore: Johns Hopkins University Press; 1998.

Key Words: education, transcatheter surgery, transcatheter aortic valve replacement, thoracic endovascular aneurysm repair, percutaneous mitral valve intervention 


\section{TABLE E1. Ovid MEDLINE search strategy}

\begin{tabular}{l}
\hline 1. cardiac surgical procedures/ \\
2. cardio* surge*.tw,kf. \\
\hline 3. cardiac surg*.tw,kf. \\
4. 1 or 2 or 3 \\
\hline 5. radiology, interventional/ \\
6. interventional radiolog*.tw,kf. \\
7. 5 or 6 \\
\hline 8. vascular surgical procedures/ \\
9. vascular surg*.tw,kf. \\
10. 8 or 9 \\
11. cardiology/ \\
12. cardiolog*.tw,kf. \\
13. interventional cardiolog*.tw,kf. \\
\hline
\end{tabular}

14. 11 or 12 or 13

15. structural heart.tw,kf.

16. 4 or 7 or 10 or 14 or 15

17. endovascular procedures/

18. endovascular.tw,kf.

19. endo vascular.tw,kf.

20. intravascular.tw,kf.

21. intra vascular.tw,kf.

22. transcatheter.tw,kf.

23. trans catheter.tw,kf.

24. wire.tw,kf.

25. wires.tw,kf

26. catheter*.tw,kf.

27. 17 or 18 or 19 or 20 or 21 or 22 or 23 or 24 or 25 or 26

28. 16 and 27

29. clinical competence/

30. "Task Performance and Analysis"/

31. competen*.tw,kf.

32. performance.tw,kf.

33. proficien*.tw,kf.

34. fundament*.tw,kf.

35. skill.tw,kf.

36. skills.tw,kf.

37. curricul*.tw,kf.

38. teach*.tw,kf.

39. train.tw,kf.

40. training.tw, $\mathrm{kf}$.

41. simulat*.tw,kf.

42.29 or 30 or 31 or 32 or 33 or 34 or 35 or 36 or 37 or 38 or 39 or 40 or 41

43. 28 and 42

44. exp education, medical, graduate/

45. trainee*.tw,kf.
TABLE E1. Continued

46. intern.tw,kf.

47. interns*.tw,kf

48. residen*.tw,kf.

49. 44 or 45 or 46 or 47 or 48

50. 43 and 49

51. exp cardiac catheterization/

52. angioplasty, balloon, coronary/

53. atherectomy, coronary/

54. exp percutaneous coronary intervention/

55. catheterization, peripheral/

56. angioplasty/

57. angioplasty, balloon/

58. cardiac catheterization.tw,kf.

59. heart catheterization.tw,kf.

60. angioplast*.tw,kf.

61. percutaneous coronary intervention.tw,kf.

62.51 or 52 or 53 or 54 or 55 or 56 or 57 or 58 or 59 or 60 or 61

63. 42 and 49 and 62

64. aortic stenosis/

65. heart valve prosthesis implantation/

66. 27 and 64 and 65

67. transcatheter aortic valve replacement/

68. tavi.tw,kf.

69. tavr.tw,kf.

70. transcatheter aortic valve implantation.tw,kf.

71. transcatheter aortic valve replacement.tw,kf.

72. 67 or 68 or 69 or 70 or 71

73. 66 or 72

74. tevar.tw,kf.

75. evar.tw,kf.

76. endovascular aortic replacement.tw,kf.

77. endovascular aortic repair.tw,kf.

78. endovascular aneurysm repair.tw,kf.

79. 74 or 75 or 76 or 77 or 78

80. Stents/

81. blood vessel prosthesis implantation/

82. stent.tw,kf.

83.80 or 81 or 82

84 . aortic aneurysm, thoracic/

85. aorta, thoracic/

86. 84 or 85

87. 83 and 86

88.79 or 87

89.73 or 88

90.42 and 49 and 89 
TABLE E1. Continued

91. advisory committees/st

92. clinical competence/st

93. certification/

94. clinical competence statement*.tw,kf.

95.91 or 92 or 93 or 94

96. 89 and 95

97. 50 or 63 or 90 or 96 